\title{
C-banding, fluorescent staining and NOR location in holokinetic chromosomes of bugs of the Neotropical genus Antiteuchus (Heteroptera: Pentatomidae: Discocephalinae)
}

\author{
Cecilia LANZONE and Maria José DE SOUZA*
}

\begin{abstract}
Departamento de Genética/CCB, Universidade Federal de Pernambuco, Av. Prof. Moraes Rego, Cidade Universitária,
\end{abstract} CEP 50732-970 Recife, Pernambuco, Brazil; e-mail: mjslopes@uol.com.br

Key words. Heteroptera, Antiteuchus, holokinetic chromosomes, C-banding, NORs, fluorochromes

\begin{abstract}
Different cytogenetic techniques including C-banding, base-specific fluorochromes and silver nitrate staining were used to compare the karyotypes of three species of bugs, representatives of the Neotropical genus Antiteuchus, namely A. mixtus, A. sepulcralis and $A$. macraspis. The species have holokinetic chromosomes which is typical of the Hemiptera, and their diploid chromosome number is $2 \mathrm{n}=14$ and they have an XX/XY (female/male) sex chromosome system. C-banding revealed telomeric blocks of constitutive heterochromatin in most chromosomes of these three species. In each species, $\mathrm{CMA}_{3}$-positive blocks were observed in the telomeric heterochromatin region of chromosome pair 1. This chromosome pair carried the nucleolar organizer region (NOR), which silver nitrate staining revealed is located in the telomeric heterochromatin. In contrast to the result obtained with $\mathrm{CMA}_{3}$, entire chromosome complement stained homogenously with DAPI, except for the telomeric region of pair 1, which remained unstained.
\end{abstract}

\section{INTRODUCTION}

Holokinetic chromosomes are a basic cytogenetic feature of true bugs (Heteroptera). Heteropteran chromosomes lack a primary constriction, the centromere, and during anaphase their chromatids move apart in parallel and do not form the classical $\mathrm{V}$-shaped form, because the spindle attachment is not localized but spread along the poleward chromosome surface (Wolf, 1996). On the other hand, Heteroptera are characterized by possessing a pre-reductional type of meiosis, which the autosomal bivalents segregate reductionally although the sex chromosomes are achiasmatic and divide equationally at the first meiotic division. The second meiosis is equational for autosomes and reductional for sex chromosomes (Ueshima, 1979).

The chromosomes of the family Pentatomidae, have been studied in a great number of species. However, only a few species have been analyzed using C-banding. For example, Camacho et al. (1985) described the pattern of heterochromatin in the karyotype of Nezara viridula. Recently, the patterns of fluorescent banding and NOR location were described in the meiotic chromosomes of the pentatomids Edessa meditabunda and E. rufomarginata (Rebagliati et al., 2003).

Analysis of the pattern in the distribution of constitutive heterochromatin in Heteroptera has revealed the presence of heterochromatic blocks restricted to the telomere regions of autosomes and sex chromosomes. Some exceptions have been reported, such as the presence of interstitial blocks visualized especially during the initial stages of meiosis (Solari, 1979; Camacho et al., 1985; Papeschi, 1991, 1995; Panzera et al., 1992). C-banding and fluorescent staining indicate details of the location and behaviour of specific types of heterochromatin in grasshoppers and bug species. In addition, these methods can elucidate chromosome characteristics not easily revealed with conventional staining (Souza et al., 1998; Grozeva \& Nokkala, 2001, 2003; Rebagliati et al., 2003; Rocha et al., 2004; Grozeva et al., 2004). In the present study, conventional staining, C-banding, fluorochromes and silver nitrate staining were used to analyze in detail the heterochromatin and nucleolar organizer regions (NORs) of three Antiteuchus species belonging to the subfamily Discocephalinae.

\section{MATERIALS AND METHODS}

Males and females of Antiteuchus mixtus (Fabricius, 1787), A. sepulcralis (Fabricius, 1803) (= Mecistorhinus sepulcralis) and A. macraspis (Perty, 1834) (= Neodine macraspis) were obtained from different populations in the northeast region of Brazil (Table 1). Chromosome preparations were made from the testicular follicles and ovarioles of adults fixed in $3: 1$ ethanol acetic acid. Cytological preparations were obtained by the classical squashing technique and chromosomes were stained with $2.0 \%$ lactic acetic orcein.

Mitotic cells were obtained from embryos as described by Souza (1991), with small modifications in terms of the period of incubation of the eggs, which was only 5 days. C-banding was performed according to the method of Sumner (1972). The technique of Schweizer et al. (1983) was used for $\mathrm{CMA}_{3} / \mathrm{DA} / \mathrm{DAPI}$ staining. Silver nitrate staining was performed as described by Suja \& Rufas (1987). The slides were observed in a Leitz Orthoplan epifluorescence microscope. The fluorochromestained material was photographed using Kodak T-MAX 400 film and Kodak Imagekink 25 film was used for the other samples. Photographic copies were obtained using Kodak Kodabrome $\mathrm{F} 3$ paper.

\section{RESULTS}

\section{Conventional staining}

Antiteuchus mixtus, A. sepulcralis and A. macraspis have a diploid chromosome number of $2 \mathrm{n}=14, \mathrm{XY}$ in the males and $2 \mathrm{n}$ $=14, \mathrm{XX}$ in females. Diploid numbers and data about the behaviour of the meiotic chromosomes of these three species of Antiteuchus were recently described by Lanzone \& Souza (2005). In general, the course of meiosis in this genus follows the typical pattern observed in Heteroptera. The species showed

\footnotetext{
* Corresponding author.
} 
TABLE 1. Collection localities and number of specimens of three species of the genus Antiteuchus analyzed.

\begin{tabular}{llcc}
\hline \multirow{2}{*}{ Species } & Localities & \multicolumn{2}{c}{ Specimens analyzed } \\
\cline { 3 - 4 } & & Male & Female \\
\hline A. mixtus & Recife-Pernambuco & 16 & 5 \\
& Pilar-Alagoas & 2 & - \\
& Rio de Contas-Bahia & 3 & - \\
& Sobradinho-Bahia & 7 & - \\
A. sepulcralis & Recife-Pernambuco & 11 & 2 \\
& Pilar-Alagoas & 2 & - \\
& Rio de Contas-Bahia & 4 & - \\
A. macraspis & Porto de Galinhas- & 6 & 3 \\
& Pernambuco & & \\
\hline
\end{tabular}

symmetrical karyotypes, with the chromosomes decreasing in size. The $\mathrm{X}$ chromosome had a size similar to that of the penultimate autosome pair. The $\mathrm{Y}$ chromosome is among the smallest, however, when compared with the $\mathrm{X}$, it varied in size among the three species. In A. macraspis and A. mixtus the $\mathrm{Y}$ is much smaller than the $\mathrm{X}$, but in A. sepulcralis it is almost equivalent in size to the $\mathrm{X}$ chromosome (Fig. 1a-c).

\section{a) 15 1) II 20 so $\begin{array}{lllllll}1 & 2 & 3 & 4 & 5 & 6 & \mathrm{XY}\end{array}$}

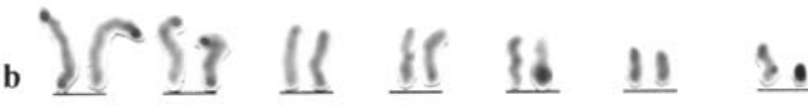
$\begin{array}{lllllll}1 & 2 & 3 & 4 & 5 & 6 & X Y\end{array}$

$611011 \pm 11010$

$\begin{array}{lllllll}1 & 2 & 3 & 4 & 5 & 6 & \mathrm{XY}\end{array}$

Fig. 1. Male mitotic chromosome complements of bugs of the genus Antiteuchus. (a) Antiteuchus macraspis, spermatogonial metaphase, conventional staining, (b) A. mixtus, spermatogonial metaphase, C-banding, and (c) A. sepulcralis, embryonic metaphase, C-banding. Bar $=10 \mu \mathrm{m}$.

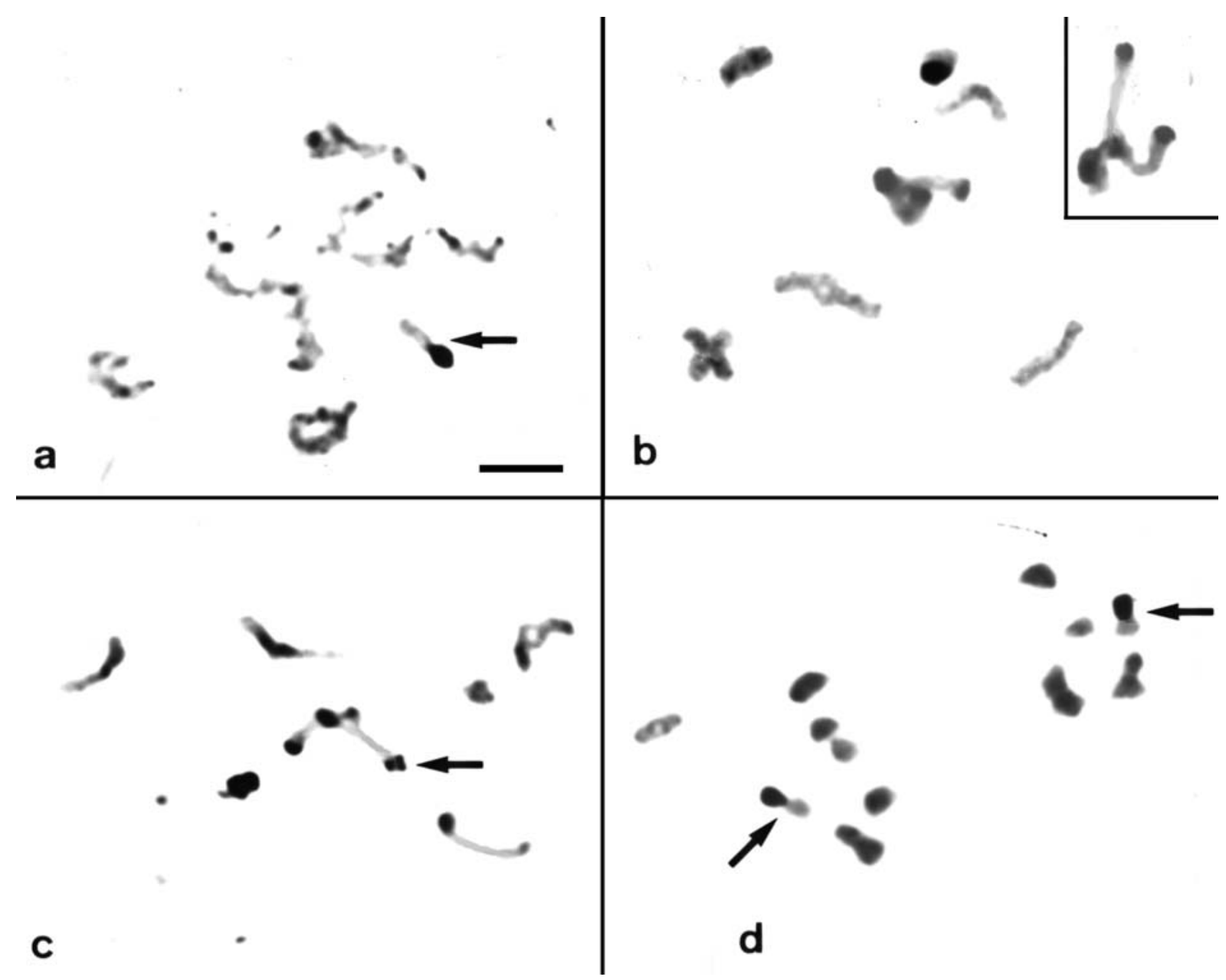

Fig. 2. C-banding pattern in meiotic chromosomes of three Antiteuchus species: (a) Pachytene in A. mixtus. Note telomeric association of sex chromosomes (arrow). (b) Diplotene in A. sepulcralis. The inset shows the pairing of the sex chromosomes and their association with the heterochromatic region of the autosome bivalent 1. (c) Diplotene in A. macraspis. One of the telomeres of autosome bivalent pair 1 (arrow) shows two heterochromatin blocks separated by a small euchromatic region. (d) Anaphase I in $A$. $m i x-$ tus. Note the close association of the sex chromosomes (arrows) Bar $=10 \mu \mathrm{m}$. 


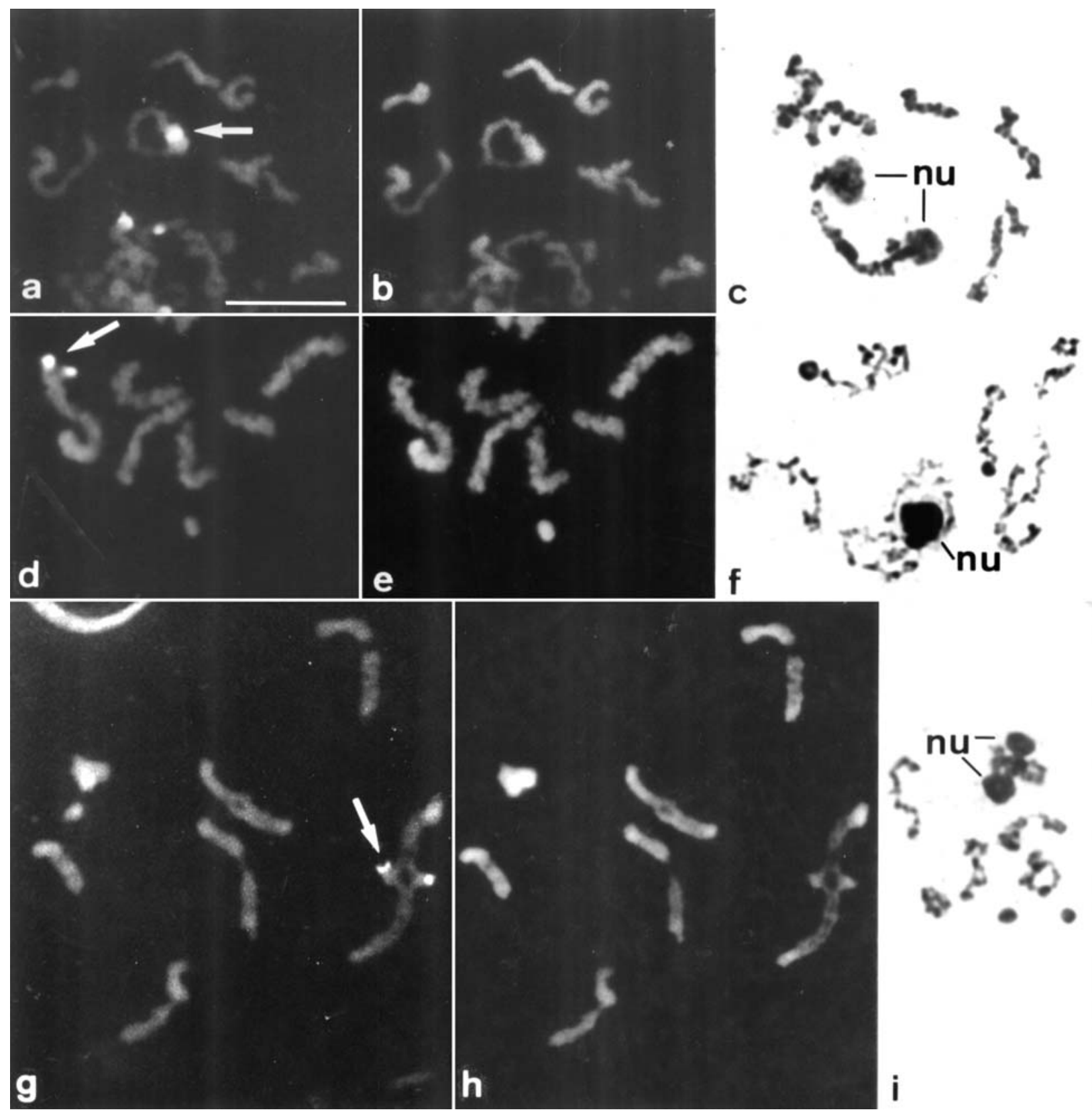

Fig. 3. $\mathrm{CMA}_{3} / \mathrm{DA} / \mathrm{DAPI}$ staining of chromosomes at pachytene in Antiteuchus mixtus (a, b) and diplotene in A. sepulcralis (d, e) and A. macraspis (g, h) respectively. (a, d, g) $\mathrm{CMA}_{3}$ images; (b, e, h) DAPI images. Arrows indicate the $\mathrm{CMA}_{3}$ positive blocks of heterochromatin. Silver nitrate staining of the nucleolar remnants (nu) in diplotene cells of Antiteuchus mixtus (c) A. sepulcralis (f) and $A$. macraspis (i). Bar $=10 \mu \mathrm{m}$.

\section{C-banding}

In the species studied, the constitutive heterochromatin detected by C-banding was restricted to the telomeric regions of the autosomes. A minute block of heterochromatin, which was difficult to detect (not shown), was observed in the $\mathrm{X}$ chromosomes in all the species. The Y chromosome, on the other hand, was completely heterochromatic in the species studied. Fig. 2a, d shows the association of the sex chromosomes in A. mixtus.

Karyotype analyses revealed that chromosome pair 1 contains the largest block of heterochromatin of all autosomes, with small differences in size being observed between the three species. Particularly large heterochromatin blocks were observed in the telomeres of pair 1 in A. sepulcralis and A. macraspis (Fig. $2 \mathrm{~b}, \mathrm{c})$. Additionally, chromosome decondensation during the ini- tial stages of prophase I revealed that one of the telomeric blocks of pair 1 of $A$. macraspis consists of two heterochromatin blocks separated by a small euchromatic region (Fig. 2c). In $A$. sepulcralis, the heterochromatic telomeres of pair 1 were frequently associated, forming a chromocenter and producing different configurations of this bivalent. The other autosomes of the three species showed very small telomeric heterochromatin blocks, which were only visible during the initial stages of meiotic prophase I. In some $A$. mixtus and $A$. macraspis preparations, the nucleolus could also be visualized by C-banding, showing that the NORs are located in the heterochromatic regions of pair 1 . In the latter species, the NOR was associated with the telomeric heterochromatin region that contained only one heterochromatin block. 


\section{Fluorochrome and silver nitrate staining}

The $\mathrm{CMA}_{3} / \mathrm{DA} / \mathrm{DAPI}$ staining revealed only one GC-rich block, which was positive for the $\mathrm{CMA}_{3}$ in the telomeric heterochromatin region of pair 1 in the three species (Fig. 3a, d, g). DAPI homogenously stained the chromosomal complement of the species, however, in the telomeric region of pair 1 , which was $\mathrm{CMA}_{3}$ positive, was totally unstained by DAPI (Fig. $3 \mathrm{~b}, \mathrm{e}, \mathrm{h}$ ). The $\mathrm{CMA}_{3}$-positive block has the same size as the $\mathrm{C}$-banding region observed in A. mixtus (Fig. 3a) and smaller than the C-band in A. sepulcralis (Fig. $3 \mathrm{~d}$ ) and A. macraspis (Fig. 3g).

Silver nitrate staining of primary spermatocytes showed the presence of a nucleolus associated with the telomeric region of pair 1 in these three species. The nucleolus could be easily identified from the beginning stages of meiotic prophase to the end of the diffuse stage. At the beginning of prophase I, the nucleolus was formed by two separate spherical bodies. As a consequence of pairing and nucleolar fusion at the beginning pachytene, only a round mass associated with the bivalent carrying the NORs was observed (Fig. 3c, f, i). During the diffuse stage two large nucleolar masses were visible, however, the nucleolus disintegrated during the later stages of meiosis.

\section{DISCUSSION}

The chromosomal complement of $2 \mathrm{n}=14, \mathrm{XY}$ (males) found in the three species studied is typical of the family Pentatomidae (Ueshima, 1979). On the other hand, the pattern of distribution of constitutive heterochromatin in the three Antiteuchus species was mainly telomeric in the autosomes and $\mathrm{X}$ chromosome, but the Y chromosome was completely heterochromatic. The same pattern is described for most heteropteran species (Solari, 1979; Panzera et al., 1992; Papeschi, 1991, 1995). Interstitial heterochromatin blocks are generally small and restricted to a few bug species (Camacho et al., 1985; Panzera et al., 1992). Another predominant characteristic of the heterochromatin patterns of the species studied was the small amount of heterochromatin in the chromosome complement, as reported for other pentatomids such as Nezara viridula and Graphosoma italicum (Camacho et al., 1985; González-García et al., 1996). Small quantities of constitutive heterochromatin are also found in the holokinetic chromosomes of damselflies (Odonata) (Prasad \& Thomas, 1992). On the other hand, heterochromatin affinities and chromosome homology have been suggested as possible factors involved in the association of the XY sex chromosome pair (Solari, 1979; Camacho et al., 1985). This type of affinity can also be related to the tendency of the sex chromosomes to associate with the telomeres of the autosomes, which possess heterochromatin in Antiteuchus species. This indicates that heterochromatin affinities are involved in sex chromosome behaviour in bugs.

C-banding and fluorochromes can be used in several ways to identify differences in the karyotypes of related species. Differences in quantity, position and staining of the heterochromatin are common in different species of insects (John et al., 1985; Moura et al., 2003; Rebagliati et al., 2003; Rocha et al., 2004) Closely related species may differ not only in the amount of heterochromatin but also in the number of heterochromatic blocks, their position and composition. The pattern in the distribution of constituitive heterochromatin has also been described for different species of Hemiptera (Kuznetsova et al., 1997; Maryanska-Nadachowska et al., 2001; Perepelov et al., 2002). Among the autosomes of the three Antiteuchus species, pair 1 contained large blocks of constitutive heterochromatin, which were easily identifiable within the karyotype and differed from those of the other autosomes, whose blocks were very small and difficult to detect. The chromosome pair 1 of $A$. sepulcralis and A. macraspis showed the largest blocks.
In the latter species, duplication of one of the telomeric heterochromatin blocks on chromosome pair 1 was observed when the chromosomes showed a greater degree of decondensation. This pattern may have resulted from a small inversion, with break points in a subterminal heterochromatic region and an internal euchromatic region. However, the absence of longitudinal differentiation in the chromosomes impairs the detection of chromosome rearrangements, which might have occurred in different heteropteran groups. Duplicate heterochromatin blocks observed in individuals from different Triatoma infestans populations are associated with extensive polymorphisms involving these regions. Mechanisms such as addition and transposition of C-positive material are suggested as a probable origin of these blocks (Panzera et al., 1992).

In $A$. mixtus, $A$. sepulcralis and $A$. macraspis, $\mathrm{CMA}_{3} / \mathrm{DA} / \mathrm{DAPI}$ staining showed that the heterochromatin stained by $\mathrm{CMA}_{3}$ is restricted to one of the telomeres of chromosome pair 1. On the other hand, DAPI produced a homogenous labelling. The pattern obtained with $\mathrm{CMA}_{3} / \mathrm{DA} / \mathrm{DAPI}$ staining permitted the characterization of heterogeneity in the heterochromatin of these species, revealing two types of constitutive heterochromatin: that restricted to chromosome pair 1, is GC-rich and that corresponding to the other heterochromatin blocks, which are not specifically GC- or AT-rich. In the three species analyzed, NORs were located on pair 1, coinciding with the only $\mathrm{CMA}_{3}$-positive block in the karyotype, indicating a GC-rich region. This pattern is also observed in the $\mathrm{X}$ chromosome of the pentatomid Graphosoma italicum (González-García et al., 1996). On the other hand, NORs are negative for $\mathrm{CMA}_{3}$ in Carlisis wahlbergi (Fossey \& Liebenberg, 1995).

Our cytogenetic data for A. mixtus, A. sepulcralis and $A$. macraspis show a high conservation of karyotypes in this genus. However, small differences in the size and structures of C-blocks affecting the largest autosomal pair, besides differences in the size of the chromosome Y, revealed by the karyotypic analysis indicate differentiation during chromosomal evolution in the genus Antiteuchus.

ACKNOWLEDGEMENTS. We thank J. Grazia (Universidade Federal do Rio Grande do Sul) for identifying of the species used in this paper. We wish to thank N. Santos for critically reading the manuscript. This work was supported by grants from the Conselho Nacional de Desenvolvimento Científico e Tecnológico $(\mathrm{CNPq})$ and Fundação de Amparo à Ciência e Tecnologia do Estado de Pernambuco (FACEPE).

\section{REFERENCES}

CAmacho J.P.M., Belda J. \& CABReo J. 1985: Meiotic behaviour of the holocentric chromosomes of Nezara viridula (Insecta, Heteroptera) analysed by C-banding and silver impregnation. Can. J. Genet. Cytol. 27: 490-497.

Fossey A. \& Liebenberg H. 1995: Meiosis and nucleolar structures in the stick bug Carlisis wahlbergi Stål. (Coreide: Heteroptera). Cytobios 81: 7-15.

GonzÁlez-García J.M., Antonio C., Suja J.A. \& Rufas J.S. 1996: Meiosis in holocentric chromosomes: kinect activity is ramdoly restricted to the chromatid ends of sex univalents in Graphosoma italicum (Heteroptera). Chromosome Res. 4: 124-132.

Grozeva S. \& NoKKala S. 2001: Chromosome numbers, sex determining systems and patterns of the C-heterochromatin in 13 species of lace bugs. Folia Biol. (Kraków) 49: 29-41.

Grozeva S. \& NoKkala S. 2003: C-heterochromatin and extra (B) chromosome distribution in six species of the Nabis (Heteroptera, Nabidae). Folia Biol. (Kraków) 51: 13-21. 
Grozeva S., Kuznetsova V.G. \& Nokkala S. 2004: Patterns of chromosome banding in four nabid species (Heteroptera, Cimicomorpha, Nabidae) with high chromosome number karyotypes. Hereditas 140: 99-104.

John B., Schweizer D. \& Mendelak M. 1985: Equilocality of heterochromatin distribution and heterochromatin heterogeneity in acridid grasshoppers. Chromosoma 91: 185-200.

Kuznetsova V.G., Maryanska-Nadachowska A. \& Nokkala S 1997: C-banded karyotype of psyllid species Alphalara calthae (L.) (Psylloidea, Homoptera, Insecta). Cytologia 62: 237-239.

Lanzone C. \& Souza M.J. 2005: Chromosome complement and meiosis in three species of the Neotropical bug genus Antiteuchus (Heteroptera, Pentatomidae, Discocephalinae). Genet. Mol. Biol. (in press).

Maryanska-Nadachowska A., Kuznetsova V.G. \& NokKala S 2001: Standard and C-banded meiotic karyotypes of Psylloidea (Sternorrhyncha, Homoptera, Insecta). Folia Biol. (Kraków) 49: 53-62.

Moura R.C., Souza M.J., Melo N.F. \& Neto A.C.L. 2003: Karyotypic characterization of representatives from Melolonthinae (Coleoptera, Scarabaeidae): Karyotypic analysis, banding and fluorescent in situ hybridization (FISH). Hereditas 138: 200-206

Panzera F., Alvarez F., Sanchez-Rufas J., Pérez R., Suja J.A., Scvortzoff E., Dujardin J.P., Estramil E. \& Salvatella R. 1992: C-heterochromatin polymorphism in holocentric chromosomes of Triatoma infestans (Hemiptera: Reduviidae). Genome 35: 1068-1074.

PAPESCHI A.G. 1991: DNA content and heterochromatin variation in species of Belostoma (Heteroptera, Belostomatidae). Hereditas 115: 109-114.

PAPESCHI A.G. 1995: Correspondence between C-banding and Ag-NOR in the sex chromosomes of Belostoma oxyurum (Belostomatidae, Heteroptera). Cytologia 60: 291-295.

Perepelov E., Brugov A.G. \& Maryanska-Nadachowska A. 2002: Constitutive heterochromatin in karyotypes of two
Cicadidae species from Japan (Cicadoidea, Hemiptera). Folia Biol. (Kraków) 50: 217-220.

Prasad R. \& Thomas H.I. 1992: C-band pattern homogeneity in dragonflies (Odonata). Caryologia 45: 57-68.

Rebagliati P.J., Papeschi A.G. \& Mola L.M. 2003: Meiosis and fluorescent banding in Edessa meditabunda and E. rufomarginata (Heteroptera: Pentatomidae: Edessinae). Eur. J. Entomol. 100: $11-18$.

Rocha M.F., Souza M.J. \& Moura R.C. 2004: Karyotypic analysis, constitutive heterochromatin and NOR distribution in five grasshopper species of the subfamily Leptysminae (Acrididae). Caryologia 57: 107-116.

Schweizer D., Mendelak M., White M.J.D. \& Contreras N. 1983: Cytogenetics of the parthenogenetic grasshopper Warramaba virgo and its bisexual relatives. X. Pattern of fluorescent banding. Chromosoma 88: 227-236.

Solari A.J. 1979: Autosomal synaptonemal complex and sex chromosomes without axes in Triatoma infestans (Reduviidae: Hemiptera). Chromosoma 72: 225-240.

SouzA M.J. 1991: Two simple methods for the preparation of mitotic and meiotic chromosomes of Orthoptera. Rev. Brasil. Genet. 14: 1079-1084.

Souza M.J., Rufas J.S. \& Orellana J. 1998: Constitutive heterochromatin, NOR location and FISH in the grasshopper Xyleus angulatus (Romaleidae). Caryologia 51: 73-80.

SuJA J.A. \& RufAS J.S. 1987: Nucleolar meiotic cycle in Orthoptera. Cell. Biol. Int. Rep. 11: 289-299.

SuMNER A.T. 1972: A simple technique for demonstrating centromeric heterochromatin. Exp. Cell Res. 75: 304-306.

Ueshima N. 1979: Hemiptera II: Heteroptera. In John B. (ed.): Animal Cytogenetics. Vol. 3. Gebrüder Borntraeger, BerlinStuttgart, pp. 1-113.

Wolf K.W. 1996: The structure of condensed chromosomes in mitosis and meiosis of insects. Int. J. Insect Morphol. Embryol. 25: 37-62.

Received April 28, 2005; revised and accepted October 31, 2005 